\title{
Esophagitis and esophageal motor abnormalities in patients with chronic spinal cord injuries
}

\author{
J G Stinneford MD, A Keshavarzian MD, B A Nemchausky MD, M I Doria MD, \\ M Durkin MD
}
Departments of Medicine and Pharmacology, Loyola University Medical Center, Maywood, Illinois; Medical, Spinal Cord Injury and Pathology Services, Hines Veterans Hospital, Hines, Illinois, USA.

To investigate the frequency and severity of esophagitis and esophageal dysmotility in patients with chronic spinal cord injury (SCI), 46 males with chronic SCI completed a questionnaire regarding gastrointestinal symptomatology. Eleven of these patients subsequently underwent upper gastrointestinal (GI) endoscopy with esophageal biopsies and 10 of the 11 also had esophageal motility studies. A significantly higher percentage of SCI patients experienced heartburn (SCI 61\%; controls (C) 40\%), esophageal chest pain (SCI 33\%; C $6.4 \%$ ), and intermittent dysphagia (SCI $30 \%$; C $8.5 \%$ ). Forty-five percent of SCI patients had endoscopic evidence of mild esophagitis, and $91 \%$ of them had histologic evidence of esophagitis. SCI patients had low amplitude, slowly propagating abnormal (double-peaked) peristatic esophageal contractions. We conclude that SCI patients experience significantly more esophageal symptoms than controls. They have a higher incidence of esophagitis and esophageal motor abnormalities. The clinical relevance of these abnormalities remains to be evaluated. Keywords: spinal cord injury; reflux esophagitis; esophageal motor
abnormalities; gastrointestinal symptomatology.

\section{Introduction}

Spinal cord injuries (SCI) represent a significant worldwide health problem, most often affecting young, otherwise healthy individuals. Historically, a spinal cord injury meant a rapid, progressive downhill course with death ensuing secondary to pulmonary, urinary or infectious complications. ${ }^{1-3}$ Fortunately, advances in the management of the acute injury have led to a marked decline in overall mortality since World War II. ${ }^{3,4}$ However, inherent in this longevity is the subsequent development of related comorbid disease which can significantly alter the quality of life.

One area of concern in this population is chronic gastrointestinal dysfunction and as-

Correspondence: Ali Keshavarzian MD, Associate Professor of Medicine, Section of Gastroenterology, Loyola Unıversity Medical Center, 2160 South First Avenue, Maywood, IL 60153, USA. sociated complications. Recent studies have demonstrated an increased incidence of abnormalities in the upper gastrointestinal tract, particularly gastric and duodenal ulceration, erosions and bleeding. ${ }^{5-9}$ These disorders may produce greater morbidity because severe cord injury can alter somatic perception thereby delaying diagnosis and therapy. ${ }^{6.7 .9}$ One might also expect patients with SCI to be at a greater risk for esophageal disease. A number of factors may predispose these individuals to gastroesophageal reflux with its associated sequelae. First, they spend a greater proportion of time in the supine or semi-upright position. Second, esophageal motor abnormalities have been described in other patient groups suffering from chronic myelopathies ${ }^{10}$ and if present may diminish acid clearance. Third, the majority of these patients will demonstrate increased intraabdominal pressure more frequently because of chronic constipation, frequent valsalva maneuvers 
and use of abdominal musculature for transfers. Esophageal function and disease in spinal cord injured patients has not previously been systemically evaluated.

For these reasons we designed a study with the following aims: (1) to determine the frequency of gastrointestinal and esophageal complaints following long-standing spinal cord injury; (2) to determine whether patients with chronic stable spinal cord injuries have a higher incidence of esophagitis and, if so, to delineate the extent and severity of the inflammation; and (3) to assess esophageal motor function in this population.

\section{Methods and patients}

\section{Patient population}

Subjects consisted of male patients admitted to the SCI service of Hines Veterans Hospital. All of the SCI were greater than one year in duration and all were judged to be neurologically stable. None of the subjects had been admitted to the unit for problems related to the gastrointestinal tract. SCI levels ranged from $\mathrm{C} 5$ to T10. Subjects were excluded if they suffered from illnesses known to alter gastroesophageal motor function such as diabetes mellitus or scleroderma or if they required chronic medication known to affect GI motility (including benzodiazapines and anticholinergics). A questionnaire was given to 46 consecutive SCI patients and following its completion all were asked to undergo esophagogastroduodenoscopy (EGD) and esophageal motility testing. Eleven of the 46 agreed to participate in endoscopy and 10 of the 11 agreed to undergo motility studies.

\section{Questionnaire}

A detailed questionnaire was administered to 46 consecutive SCI males in order to quantify the nature and intensity of any long-standing GI symptomatology. Data were compared with 47 male controls of similar ages admitted to the Veterans Hospital with medical problems unrelated to the GI tract. GI complaints evaluated included frequency of defecation as well as presence and severity of heartburn, nausea, vomiting, dysphagia, chest pain of esophageal origin (defined as food related and/or relieved with antacids), fullness after meals and abdominal pain. A severity index was calculated using the product of the frequency of a given symptom per week and its severity (assessed by a visual analog of 0-10). Each patient was asked whether he had a given symptom (regardless of its severity) during the last year. If the answer was positive, then he was asked to determine the frequency of the episodes of the symptom (regardless of the duration of severity) per week. Then he was asked to indicate the severity of the symptom (regardless of its frequency) by marking on a $10 \mathrm{~cm}$ graduated line. The questionnaire was administered to each and every patient by one of the authors (JGS).

\section{Assessment of esophagitis}

Upper GI endoscopy (EGD) was performed on 11 male volunteers with chronic SCI as defined above (age range 25-60); mean 50.5 yrs). These subjects were similar to the remaining 32 patients with regard to age as well as frequency and severity of GI symptoms (Table I). The results were compared with 18 asymptomatic males admitted to the Veterans Administration alcohol detoxification unit (age range 31-60; mean 44 yrs). These alcoholic controls happened to have no esophageal symptoms regularly (monthly) at the time of the EGD. Their last alcoholic drink was at least 3 days (range 3-14 days) prior to the EGD. Prior to undergoing EGD all subjects were asked to fast overnight. Intravenous sedation was achieved with midazolam (Roche Laboratories, Nutley, NJ). The oropharynx was anesthetized with tetracaine applied topically. An Olympus GIFXQ10 endoscope (Olympus, Lake Success, NY) was utilized and three forceps pinch biopsies were obtained at each of two sites $2 \mathrm{~cm}$ and $5 \mathrm{~cm}$ above the gastroesophageal junction. Endoscopic appearance was graded according to previously published criteria. ${ }^{11}$ The grading scale was as follows: grade 0 , no mucosal abnormalities; grade 1, no macroscopic erosions but erythema, hyperemia, or mucosal friability; grade 2, superficial erosions involving $<10 \%$ of the mucosal surface of the last $5 \mathrm{~cm}$ of esophageal squamous mucosa; 


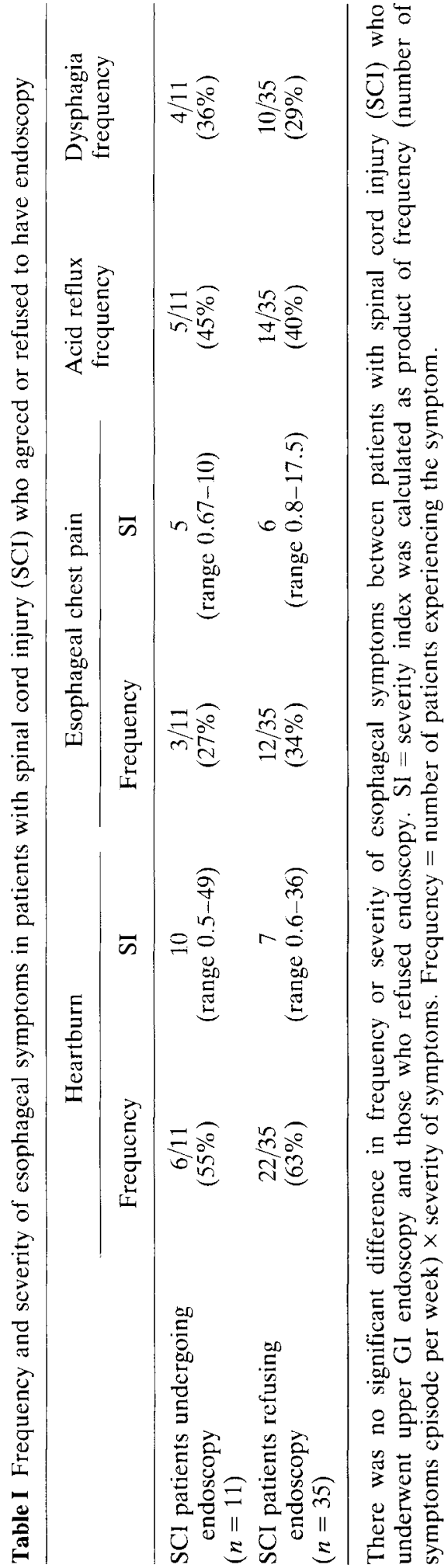

grade 3, superficial erosions or ulceration involving $10-50 \%$ of the mucosal surface of the last $5 \mathrm{~cm}$ of esophageal sqaumous mucosa; grade 4, deep peptic ulceration anywhere in the esophagus or confluent erosion of $>50 \%$ of the mucosal surface of the last $5 \mathrm{~cm}$ of esophageal squamous mucosa. All three biopsy specimens from each of two sites were oriented on filter paper and histologic evaluation was performed by an investigator blinded to the endoscopic findings. The presence of histologic esophagitis was assessed according to previously reported criteria. ${ }^{12-14}$ Esophagitis was considered to be present if both the basal cell layer and papillae were hypertrophied to greater than $50 \%$ of the specimen thickness. The presence of neutrophils in the lamina propria was considered to be supportive evidence of esophagitis.

\section{Assessment of esophageal motility}

Ten of the 11 SCI subjects evaluated for reflux esophagitis also underwent esophageal manometry. One subject refused further investigation. These data were compared with a control group which consisted of 13 healthy male asymptomatic volunteers (age range 24-39; mean 31 yrs). Esophageal manometry was performed utilizing an eight-lumen esophageal catheter with a $6 \mathrm{~cm}$ Dent sleeve and high-pressure, low-compliance infusion system (Arndorfer Medical Specialists Inc, Greendale, WI). Intraluminal pressures were transmitted by water-filled catheters to external transducers (Sensormedics Transducers and Dynograph, Anaheim, CA). The recording catheters were arranged to measure pressure through side orifices, spaced at $3 \mathrm{~cm}$ intervals. The infusion rate was $0.5 \mathrm{ml} / \mathrm{min}$ at each orifice. Sensitivity of the system was $400 \mathrm{mmHg} / \mathrm{s}$. Lower esophageal sphincter pressure (LESP) was measured by a Dent sleeve. Intragastric pressure was continuously measured by a catheter distal to the sleeve and LESP was measured against intragastric pressure which was considered to have a value of zero. Peristaltic amplitude, duration and velocity in response to wet swallows ( $5 \mathrm{ml}$ intraoral water bolus) at 30 -second intervals were assessed at $3 \mathrm{~cm}$, $6 \mathrm{~cm}$ and $9 \mathrm{~cm}$ above the LES. 


\section{Statistical analysis}

The statistical significance of the results was assessed by the Mann-Whitney $U$ test when GI symptomatology/symptom indexes were compared between SCI patients and controls, and chi-square when the frequency of symptoms were compared. The frequency of esophagitis was compared utilizing the chi-square test and differences in motility results were analyzed with Student's $t$ test. A probability value of $<0.05$ was considered significant.

\section{Results}

Frequency and severity of gastrointestinal symptoms

Patients with chronic SCI reported a significantly higher number of GI complaints when compared to controls, especially with regard to esophageal symptomatology (Table II). A significantly higher percentage of SCI patients reported heartburn, dysphagia, esophageal chest pain and abdominal pain. In addition, their symptoms were significantly more frequent and more severe than controls (Table III). Eleven of 28 symptomatic SCI patients (39\%) had weekly heartburn and 20 patients $(71 \%)$ had monthly heartburn. In contrast, only 3 $(16 \%)$ and $9(47 \%)$ of symptomatic controls had weekly and monthly heartburn respectively. Similarly, 7 (47\%) and 9 of $15(60 \%)$ symptomatic SCI patients had weekly and monthly esophageal chest pain respectively; while one of 3 symptomatic controls had weekly chest pain. Frequent abdominal pain was also significantly more common in symptomatic SCI patients: 17 of $24(71 \%)$ had weekly pain and $20(83 \%)$ had monthly pain. Monthly abdominal pain was reported by 3 controls.

Nausea, vomiting and postprandial fullness were not significantly different between the two groups. None of the 46 SCI patients

Table II Frequency of GI symptoms in patients with spinal cord injury (SCI)

\begin{tabular}{lcccc}
\hline & $\begin{array}{c}\text { Heartburn } \\
\text { frequency }\end{array}$ & $\begin{array}{c}\text { Esophageal chest pain } \\
\text { frequency }\end{array}$ & $\begin{array}{c}\text { Abdominal pain } \\
\text { frequency }\end{array}$ & $\begin{array}{c}\text { Dysphagia } \\
\text { frequency }\end{array}$ \\
\hline $\begin{array}{l}\text { SCI patients } \\
(n=46)\end{array}$ & $28 / 46^{\mathrm{a}}$ & $15 / 46^{\mathrm{a}}$ & $24 / 46^{\mathrm{a}}$ & $14 / 46^{\mathrm{a}}$ \\
Controls & $(61 \%)$ & $(33 \%)$ & $(52 \%)$ & $(30 \%)$ \\
$(n=47)$ & $19 / 47$ & $3 / 47$ & $4 / 47$ & $4 / 47$ \\
\hline
\end{tabular}

Significantly higher numbers of patients with spinal cord injuries (SCI) reported episodes of heartburn, esophageal chest pain and dysphagia than control groups. Frequency $=$ number of patients experiencing the symptom. ${ }^{a} p<0.05$ SCI patients versus controls.

Table III Severity of GI symptoms in patients with spinal cord injury (SCI)

\begin{tabular}{|c|c|c|c|c|c|c|}
\hline & \multicolumn{2}{|c|}{ Heartburn } & \multicolumn{2}{|c|}{ Esophageal chest pain } & \multicolumn{2}{|c|}{ Abdominal pain } \\
\hline & $\begin{array}{l}\text { Frequency } \\
\text { of episodes }\end{array}$ & SI & $\begin{array}{l}\text { Frequency } \\
\text { of episodes }\end{array}$ & SI & $\begin{array}{l}\text { Frequency } \\
\text { of episodes }\end{array}$ & SI \\
\hline $\begin{array}{l}\text { SCI patients } \\
(n=46)\end{array}$ & $1.3^{\mathrm{a}}$ & $7.2^{\mathrm{a}}$ & $1.3^{\mathrm{a}}$ & $4.6^{\mathrm{a}}$ & $3.1^{\mathrm{a}}$ & $16.2^{\mathrm{a}}$ \\
\hline $\begin{array}{l}\text { Controls } \\
(n=47)\end{array}$ & 0.4 & 5.8 & 0.4 & 2.4 & 0.7 & 4.8 \\
\hline
\end{tabular}

Patients with SCI reported significantly more severe and more frequent episodes of heartburn, chest pain, and abdominal pain. SI $=$ severity index $=$ frequency/week $\times$ visual analog scale. Frequency of episodes $=$ number of symptom episodes per week. ${ }^{a} p<0.05$ SCI patients versus control subjects. 
had spontaneous bowel movements and each required a specific program of bowel care to minimize constipation.

\section{Assessment of esophagitis}

In the SCI group 91\% (10 of 11 ) demonstrated histologic evidence of significant esophagitis compared to 6\% (1 of 18) of asymptomatic controls (Fig 1). Every SCI patient judged to have reflux esophagitis met all three histologic criteria in at least one biopsy specimen. The endoscopic findings did not correlate well with the histologic evaluation. One subject received an endoscopic score of 2 and 4 additional subjects received a score of 1 . The remaining 6 had normal appearing esophageal mucosa (Fig 2). No esophageal stricture was noted in any of the patients studied. None of the 18 control subjects demonstrated endoscopic evidence of esophagitis.

\section{Assessment of esophageal motility}

The esophageal contraction amplitude (ECA) in SCI patients was significantly lower than in controls when measured at $9 \mathrm{~cm}$ and $6 \mathrm{~cm}$ above the LES (Fig 3). ECA at $3 \mathrm{~cm}$ above the LES was also lower than in controls but this difference was not statistically significant. The esophageal contraction velocity $(\mathrm{ECV})$ in SCI patients was significantly slower than in controls only in

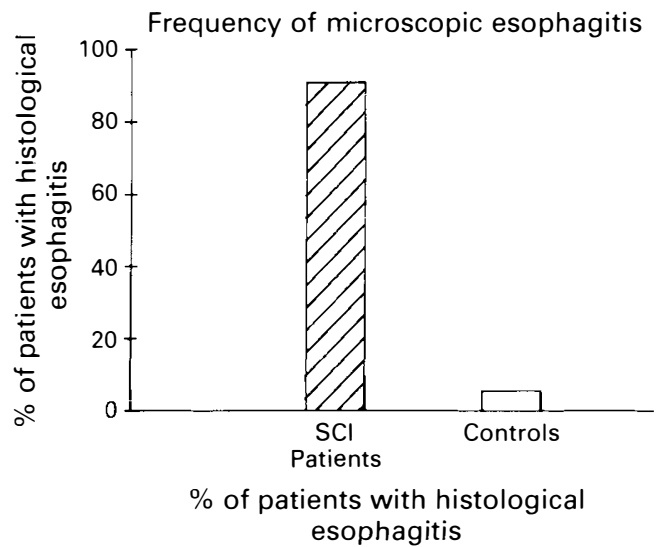

Figure 1 Patients with chronic spinal cord injuries (SCI) demonstrated a significantly higher frequency of histologic esophagitis.

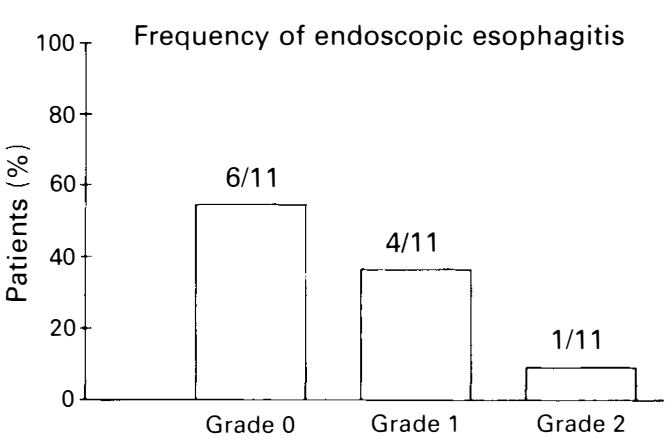

Figure 2 Endoscopic grading of esophageal mucosa in spinal cord injured patients correlated poorly with histologic findings.

Amplitude of esophageal contractions in patients with spinal cord injury

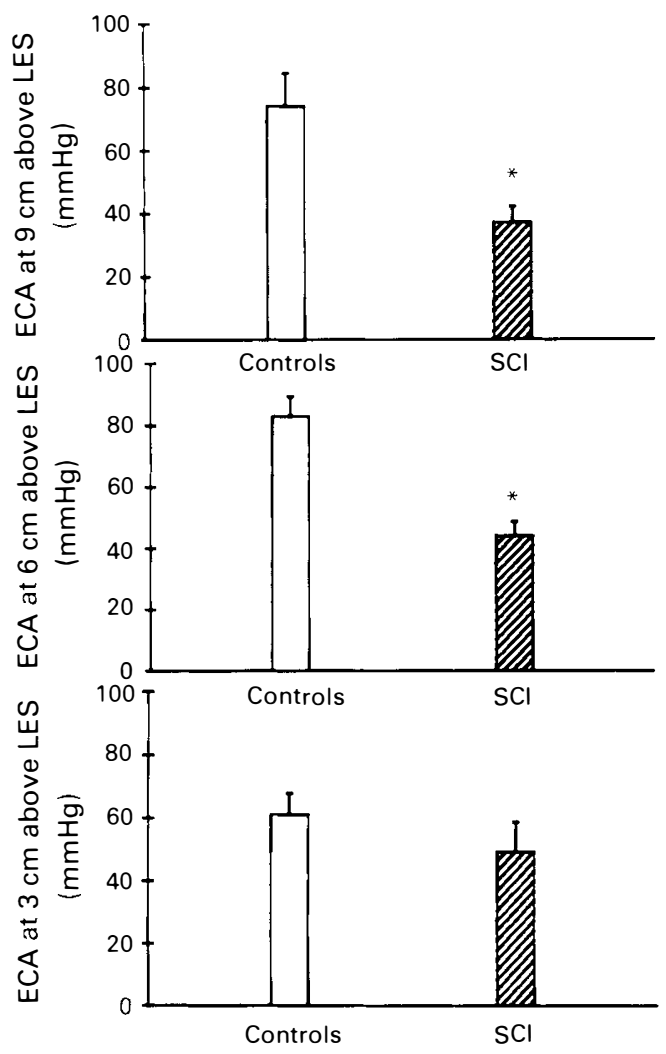

Figure 3 The esophageal contraction amplitude (ECA) was significantly lower in spinal cord injured patients at $9 \mathrm{~cm}$ and $6 \mathrm{~cm}$ above the LES but not at $3 \mathrm{~cm}$. 
the proximal esophagus (Fig 4). The esophageal contraction duration was similar in both groups. Sixty percent of the SCI patients demonstrated a higher frequency of double-peaked contractions (defined as greater than $20 \%$ of total contractions) compared to $5 \%$ of controls. Of the increased double-peaked contractions in the SCI group, $50 \%$ occurred in the proximal esophagus, $17 \%$ in the distal esophagus and $33 \%$ throughout the esophagus. Thirty percent of the SCI group also demonstrated repetitive contractions compared to none of the controls. No significant differences were noted in LESP or percent of LES relaxation in response to swallowing between either group (Table IV).

\section{Discussion}

As the initial resuscitation and management of acute spinal cord injuries continue to improve, more SCI patients may develop chronic, often debilitating sequelae to their injuries. The chronicity of these problems merely adds to the overall frustration and depression most individuals experience after SCI, a fact which may be reflected in the rising suicide rate amongst younger SCI patients. ${ }^{1}$ In addition, while overall mortality has declined, life expectancy remains lower than normal, with such cause-specific deaths as pulmonary and cardiovascular disease being more frequent than agematched controls. ${ }^{1.2}$ For these reasons, it is desirable to better delineate the nature and extent of comorbid disease in SCI patients so that appropriate long-term treatment strategies can be developed.

In this study we addressed one such health concern-namely, gastroesophageal reflux disease (GERD). We also attempted to better define GI complaints, especially those related to the esophagus, in the context of a chronic SCI. Esophageal motor function was assessed because of the close relationship between abnormal esophageal motility and GERD in patients without SCI.

Gerd is a common entity within the general population and one would expect this to hold true for SCI patients as well. Indeed our study demonstrated the presence of mild esophagitis in a high percentage of SCI patients. The underlying cause of this problem is not clear. However, many aspects of the cord injury would seem to place these patients at a higher risk for reflux. A number of recent studies have demonstrated that GERD likely represents a multifactorial process with inflammation occurring secondary to imbalances between esophageal acid exposure and mucosal protection. ${ }^{15-17}$ These imbalances become particularly important when considering the SCI population.

Dent et al noted that induction of transient lower esophageal sphincter relaxation (TLESR) in normal subjects with artificially increased intraabdominal pressure led to significant reflux episodes approximately $80 \%$ of the time. ${ }^{16}$ Similarly, Holloway and colleagues elicited a marked increase in
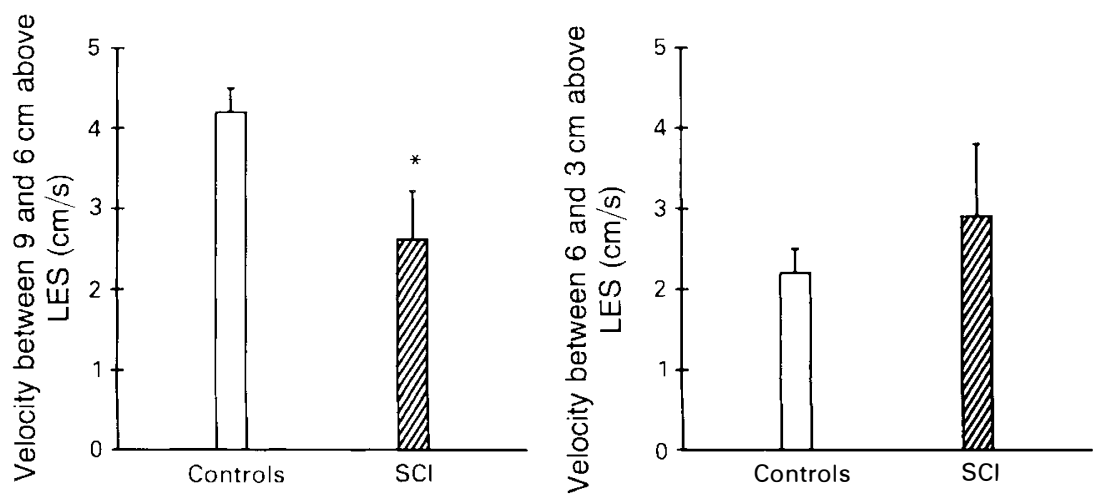

Figure 4 The esophageal contraction velocity was significantly slower proximally in spinal cord injured patients. No difference was noted in the distal esophagus. 
Table IV Demographic characteristics and esophageal findings in patients with spinal cord injury (SCI)

\begin{tabular}{|c|c|c|c|c|c|c|c|c|}
\hline Patient & Age & $\begin{array}{l}\text { Level of } \\
\text { injury }\end{array}$ & $\begin{array}{l}\text { Esophageal } \\
\text { symptoms }^{\text {a }}\end{array}$ & $\begin{array}{l}\text { Histologic } \\
\text { esophagitis }\end{array}$ & $\begin{array}{l}\text { Macroscopic } \\
\text { grading }\end{array}$ & $\begin{array}{c}\text { LESP } \\
(\mathrm{mmHg})\end{array}$ & $\begin{array}{c}\text { Esophageal } \\
\text { contraction } \\
\text { amplitudeb } \\
(\mathrm{mmHg})\end{array}$ & $\begin{array}{l}\text { Esophageal } \\
\text { contraction } \\
\text { velocity } \\
(9 \text { to } 6 \mathrm{~cm} / \mathrm{s})\end{array}$ \\
\hline 1 & 48 & T4-5 & $\mathrm{H}$ & Yes & 1 & 14 & $\begin{array}{l}6 \mathrm{~cm}=75 \\
9 \mathrm{~cm}=41\end{array}$ & 4.7 \\
\hline 2 & 57 & $\mathrm{~T} 10$ & None & Yes & 1 & 23 & $\begin{array}{l}6 \mathrm{~cm}=43 \\
9 \mathrm{~cm}=43\end{array}$ & 1 \\
\hline 3 & 54 & C5-6 & None & Yes & 0 & 18 & $\begin{array}{l}6 \mathrm{~cm}=37 \\
9 \mathrm{~cm}=25\end{array}$ & 2.9 \\
\hline 4 & 25 & C5-6 & $\mathrm{H}, \mathrm{D}, \mathrm{E}$ & Yes & 1 & 20 & $\begin{array}{l}6 \mathrm{~cm}=59 \\
9 \mathrm{~cm}=64\end{array}$ & 1.4 \\
\hline 5 & 32 & T5-6 & $\mathrm{H}, \mathrm{A}$ & Yes & 2 & 16 & $\begin{array}{l}6 \mathrm{~cm}=56 \\
9 \mathrm{~cm}=26\end{array}$ & 4.6 \\
\hline 6 & 56 & T5-6 & $\mathrm{H}, \mathrm{D}, \mathrm{E}, \mathrm{A}$ & Yes & 0 & 12 & $\begin{array}{l}6 \mathrm{~cm}=32 \\
9 \mathrm{~cm}=30\end{array}$ & 1 \\
\hline 7 & 58 & T9 & $\mathrm{H}, \mathrm{D}, \mathrm{E}$ & Yes & 0 & 13 & $\begin{array}{l}6 \mathrm{~cm}=35 \\
9 \mathrm{~cm}=48\end{array}$ & 3.2 \\
\hline 8 & 60 & $\mathrm{~T} 2-3$ & $\mathrm{D}, \mathrm{A}$ & Yes & 0 & 13 & $\begin{array}{l}6 \mathrm{~cm}=30 \\
9 \mathrm{~cm}=10\end{array}$ & 5 \\
\hline 9 & 57 & C5-6 & $\mathrm{H}, \mathrm{A}$ & Yes & 0 & 14 & $\begin{array}{l}6 \mathrm{~cm}=31 \\
9 \mathrm{~cm}=27\end{array}$ & 3 \\
\hline 10 & 58 & C5-6 & A & Yes & 0 & 17 & $\begin{array}{l}6 \mathrm{~cm}=48 \\
9 \mathrm{~cm}=58\end{array}$ & 1.5 \\
\hline 11 & 66 & T5-6 & None & No & 0 & ND & ND & ND \\
\hline
\end{tabular}

${ }^{\mathrm{a}} \mathrm{H}=$ heartburn, $\mathrm{D}=$ dysphagia, $\mathrm{E}=$ esophageal chest pain, $\mathrm{A}=$ acid reflux. ${ }^{\mathrm{b}}$ Amplitude and velocity of esophageal contraction measured at $6 \mathrm{~cm}$ and $9 \mathrm{~cm}$ above LES; normal: $9 \mathrm{~cm}=74 \pm 11 \mathrm{mmHg}, 6 \mathrm{~cm}=85 \pm 6 \mathrm{mmHg}, 9$ to $6 \mathrm{~cm}=4.2 \pm 0.3 \mathrm{~cm} / \mathrm{s}$. LESP $=$ lower esophageal sphincter pressure. $\mathrm{ND}=$ not done. 
TLESR in both normals and patients with documented reflux when intragastric pressure was increased with balloon distension. ${ }^{18}$ These findings would appear to be significant in the setting of a chronic SCI because, as stated in the introduction, these patients demonstrate frequent episodes of increased intraabdominal pressure. This elevation in intraabdominal pressure could, therefore, predispose these patients to more frequent TLESR with the subsequent reflux of gastric contents into the esophageal lumen. This concept is supported by the observations of Gore and coworkers who noted an increased frequency of gastroesophageal reflux in SCI patients undergoing barium studies. ${ }^{5}$ However, studies with 24-hour esophageal $\mathrm{pH}$ measurement is needed to determine whether gastroesophageal reflux is more frequent or more severe in these patients. We initially planned to perform 24-hour $\mathrm{pH}$ studies in our patients. Unfortunately, none of our patients agreed to undergo such a test.

Another important pathophysiologic component of reflux esophagitis is the length of exposure of esophageal mucosa to gastric contents. Studies have shown that esophageal acid clearance is dependent on normal primary peristaltic function (volume clearance) and acid neutralization with salivary bicarbonate. ${ }^{19}$ Kahrilas et al demonstrated a positive correlation between peristaltic dysfunction and ineffective volume clearance from the esophageal lumen. ${ }^{20}$ Therefore, esophageal dysmotility may increase the risk of reflux esophagitis by diminishing acid clearance. Esophageal motor abnormalities have been described in patients with chronic myelopathies ${ }^{10}$ but have not been previously studied in the SCI population.

In the present study, both the amplitude and the velocity of esophageal contractions were significantly lower in SCI patients than in controls. The SCI group also demons- trated a higher frequency of abnormal contractions which may contribute to overall peristaltic dysfunction. Similar esophageal motor disturbances have been described in patients with GERD. ${ }^{17}$ These abnormalities may increase the acid exposure time, but direct measurement of acid clearance in the SCI population is necessary for confirmation.

It is also possible that these motor abnormalities are a consequence of reflux disease rather than causative. Our study cannot exclude this possibility since our control subjects had no esophagitis. Further studies are needed to compare esophageal motility SCI patients with esophagitis with SCI patients without esophagitis.

The LESP and percent LES relaxation were normal in our SCI group. This is not unexpected given the fact that vagal innervation remains intact in the majority of cord injuries.

Interestingly, chronic SCI patients did not experience more nausea, vomiting or postprandial fullness implying that clinically significant gastric dysmotility may not be present in the majority of SCI patients. This is supported by a recent study demonstrating normal gastric emptying in chronic SCI patients. $^{21}$

Finally, the endoscopic mucosal grading correlated poorly with the presence or absence of histologic esophagitis in our study. This is not surprising and is consistent with other studies comparing endoscopic appearance to histologic evaluation, especially when the inflammatory changes are mild. ${ }^{22}$

It remains to be seen whether early recognition of gastroesophageal reflux combined with prompt intervention in the disease process will decrease aspiration pneumonia and other complications of GERD as well as significantly improve the lives of patients with chronic spinal cord injuries.

\section{References}

1 DeVivo MJ, Kartus PL, Stover SL, Rutt RD, Fine PR (1989) Cause of death for patients with spinal cord injuries. Arch Intern Med 149: 1761-1766.

2 Reines HD, Harris RL (1987) Pulmonary complications of acute spinal cord injuries. Neurosurgery 2: 193-196.

3 Carter RE (1987) Respiratory aspects of spinal cord injury management. Paraplegia 25: 262-266. 
4 DeVivo MJ, Kartus PL, Stover SL, Rutt RD, Fine PR (1987) Seven-year survival following spinal cord injury. Arch Neurol 44: 872-875.

5 Gore RM, Mintzer RA, Calenoff L (1981) Gastrointestinal complications of spinal cord injury. Spine 6: 538-544.

6 Ingersoll GL (1985) Abdominal pathology in spinal cord injured persons. J Neurosurg Nursing 17: $343-348$.

7 Charney KJ, Juler GL, Comarr AE (1975) General surgical problems in patients with spinal cord injuries. Arch Surg 110: 1083-1088.

8 Tanaka M, Uchiyama M, Kitano M (1979) Gastroduodenal disease in chronic spinal cord injuries. Arch Surg 114: 185-187.

9 Kewalramani LS (1979) Neurogenic gastroduodenal ulceration and bleeding associated with spinal cord injuries. J Trauma 19: 259-265.

10 Fischer RA, Ellison GW, Thayer WR, Spiro HW, Glaser GH (1965) Esophageal motility in neuromuscular disorders. Ann Intern Med 63: 229-248.

11 Hetzel DJ, Dent J, Reed WD, Narielvala FM, Mackinnon M, McCarthy JH (1988) Healing and relapse of severe peptic esophagitis after treatment with omeprazole. Gastroenterology 95: 903-912.

12 Ismail-Beigi F, Horton PF, Pope CE (1970) Histological consequences of gastroesophageal reflux in man. Gastroenterology 58: 163-174.

13 Black DD, Haggitt RC, Orenstein SR, Whitington PF (1990) Esophagitis in infants. Gastroenterology 98: $1408-1414$.

14 Winter HS, Madara JL, Stafford RJ, Grand RJ, Quinlan J, Goldman H (1982) Intraepithelial eosinophils: a new diagnostic criterion for reflux esophagitis. Gastroenterology 83: 818-823.

15 Dodds WJ (1988) The pathogenesis of gastrointestinal reflux disease. AJR 151: 49-56.

16 Dent J, Dodds WJ, Hogan WJ, Toouli J (1988) Factors that influence induction of gastroesophageal reflux in normal human subjects. Dig Dis Sci 33: 270-275.

17 Cucchiari S, Staiano A, DiLorenzo C, DiLuca G, della-Rocca A, Auricchio S (1988) Pathophysiology of gastroesophageal reflux and distal esophageal motility in children with gastroesophageal reflux disease. $J$ Pediatr Gastroenterol Nutr 7: 830-836.

18 Holloway RH, Hongo M, Berger K, McCallum RW (1985) Gastric distension: a mechanism for postprandial gastroesophageal reflux. Gastroenterology 89: 779-784.

19 Helm JF, Dodds WF, Pelc LR, Palmer DW, Hogan WJ, Teeter BC (1984) Effect of esophageal emptying and saliva on clearance of acid from the esophagus. NEJM 310: 284-288.

20 Kahrilas PJ, Dodds WJ, Hogan WJ (1988) Effect of peristaltic dysfunction on esophageal volume clearance. Gastroenterology 94: 73-80.

21 Rajendran SK, Reiser JR, Korsten MA, Zhang RL, Bauman WA (1991) Gastrointestinal transit after spinal cord injury: effect of cisapride. Gastroenterology 100: 484 (abstract).

22 Behar J, Biancani P, Sheahan DG (1976) Evaluation of esophageal tests in the diagnosis of reflux esophagitis. Gastroenterology 71: 9-15. 